\title{
Prediction of the Lightning Location for Transmission Systems using the characteristics of transient current waveform and travelling wave method
}

\author{
Prailkanok Lertwanitrot $^{\mathrm{a}, *}$, Atthapol Ngaopitakkul ${ }^{\mathrm{a}}$ and Sulee Bunjongjit ${ }^{\mathrm{b}}$ \\ ${ }^{a}$ Faculty of Engineering, King Mongkut's Institute of Technology Ladkrabang, \\ Chalongkrung Road, Ladkrabang, Bangkok, 10520, Thailand \\ ${ }^{\mathrm{b}}$ Faculty of Engineering, Rajamangala University of Technology Rattanakosin, \\ Phutthamonthon Sai 5 Road, Salaya Phutthamonthon Nakhon Pathom, 73170, Thailand \\ *Corresponding Author: prailkanok@gmail.com, knatthap@kmitl.ac.th
}

\begin{abstract}
This paper proposes the travelling wave technique to predict the location of lightning on the transmission line. The conditions of lightning striking on the conductor of 115 $\mathrm{kV}$ Thailand's transmission line were simulated using ATP/EMTP program. The case studies were performed with changing various parameters such as inception angle, location of lightning, ground resistance of tower, amplitude of lightning strikes, and voltage level of transmission line, in order to evaluate the accuracy of the proposed technique. The characteristics of first peak time of current waveform are investigated as input data for travelling wave equation. The obtained results show that, the first peak time only tends to decrease with decreasing distance between the substation so that the lightning location can be calculated and gives a satisfactory accuracy.
\end{abstract}

Keywords: Lightning, Lightning location, Transmission line, Travelling wave, Transient.

\section{Introduction}

Nowadays, the technology is more developed and the population is increasing so it makes the demand of electricity increased. Hence, the transmission network has been expanded to transfer the electrical energy into wide area with the economic growth. Stability of power system is important because it is an indicator of the reliability of the system. Lightning is a natural event that can occur and cause malfunction to some electrical systems. When the lightning occurs, the transmission system could be damaged and then the transmission system is not reliable from the power outage. Therefore, the behavior of lightning is necessary to make the electricity authority able to decrease damage because of the power outage. In the literature for lightning, there are many research studies ${ }^{(1-23)}$ such as shielding failures ${ }^{(1-5)}$, lightning current ${ }^{(6-7)}$, flashover ${ }^{(8-9)}$, and lightning impluse test ${ }^{(21-22)}$. Although most of power outage causes the shielding failures but, when lightning strike on a transmission line, location of lightning should be analysed in order to rapidly repair the transmission system.

Hence, this paper is interested in predicting the location of lightning striking along transmission line. In previous paper ${ }^{(23)}$, the characteristics of the all phase current waveform in terms of the peak amplitude current and the first peak time were analysed about the variation of current waveforms. The obtained results showed that the variation of characteristics of transient current would be very useful in the development of lightning location scheme, so the travelling wave technique was considered in order to calculate the location of lightning. Generally, traveling wave method was divided into 4 types such as type A, type B, type C, and type D. In this paper, travelling wave equation of type $\mathrm{D}$ was used for calculating the location of lightning because travelling wave equation of type D used input data from double end substation, and did not depend on the reflection of travelling wave from substation. Moreover, the various parameters such as inception angle, location of lightning, ground resistance of tower, amplitude of lightning strikes, and voltage level of transmission line, are varied and compared in order to evaluate the accuracy of the proposed technique. 


\section{Simulation and Results}

The $115 \mathrm{kV}$ double circuit transmission system which is a part of Electricity Generating Authority Thailand (EGAT) was simulated with ATP/EMTP program as shown in Fig. 1. By considering the Fig. 1, the length of transmission line was $88.5 \mathrm{~km}$, interconnected between the sending end substation (RY2) and the receiving end substation (CT) while the current transformers (CTs) were installed at each end substation in order to detect the lightning current. Moreover, the total connected load (30 MVA, $115 \mathrm{kV}$, and 0.8 lagging pf.) was installed at the receiving end substation $(\mathrm{CT})$.

To study the characteristics of current waveform, the various case studies are performed with following changes of the parameters:

- Locations of lightning on the transmission line are the length of $10 \%, 30 \%, 50 \%$, and $70 \%$, measured from the sending end substation (RY2).

- Inception angles on a voltage phase A waveform are $0^{\circ}, 90^{\circ}$, and $135^{\circ}$.

- The amplitudes of lightning strikes are varied as 10 $\mathrm{kA}, 20 \mathrm{kA}$, and $30 \mathrm{kA}$.

- The voltage levels of transmission system are $115 \mathrm{kV}$, $230 \mathrm{kV}$, and $500 \mathrm{kV}$.
- The ground resistances of transmission system tower are varied as $1 \Omega, 10 \Omega$, and $100 \Omega$.

After simulating the lighting strikes on the conductor of transmission line, the all phase current waveform was measured from the current transformers of each substation. After measuring the current waveform, it can be observed that all phase current has a sudden change and increases in short period of time as shown in Fig. 1. This indicates that the abnormal condition occurs on the transmission system. For the next step, the all phase current waveform obtained from the simulation results was calculated with Clarke's transformation so that the positive sequence current can be achieved as shown in Fig. 2 to Fig. 6.

After calculating the positive sequence current, by considering the Fig. 2 and Table 1, the case studies are divided into 4 cases, corresponding with location of lightning along the length of transmission line. By carefully considering the Fig. 2, the peak amplitude of positive sequence current of sending end substation decreases when increasing the location of lightning while the first peak time of positive sequence current tends to increase with the increase of the location of lightning as shown in Table 1. This indicates that the first peak time can be beneficial for predicting the lightning location on the transmission line.
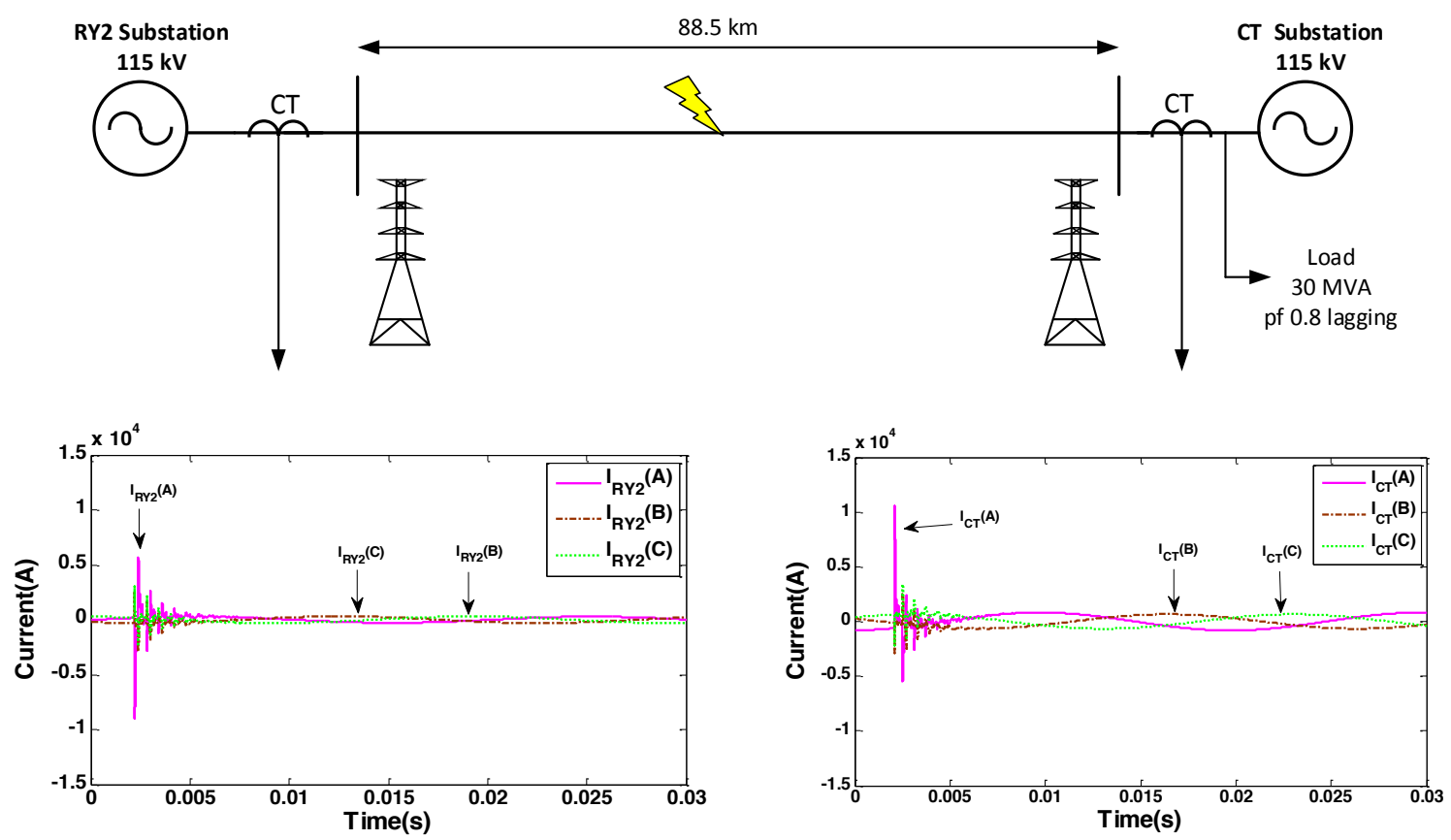

Fig. 1 One line diagram of the simulation circuit ${ }^{(23)}$. 


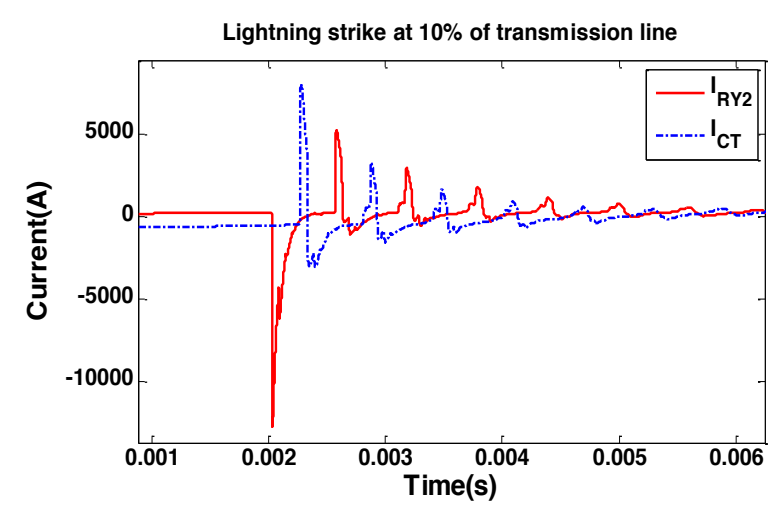

(a) Lightning strike at $10 \%$ of transmission line.

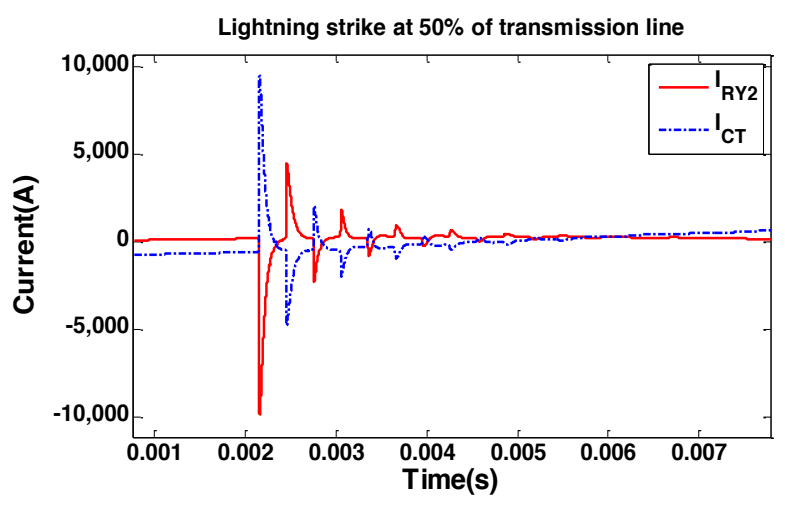

(c) Lightning strike at $50 \%$ of transmission line

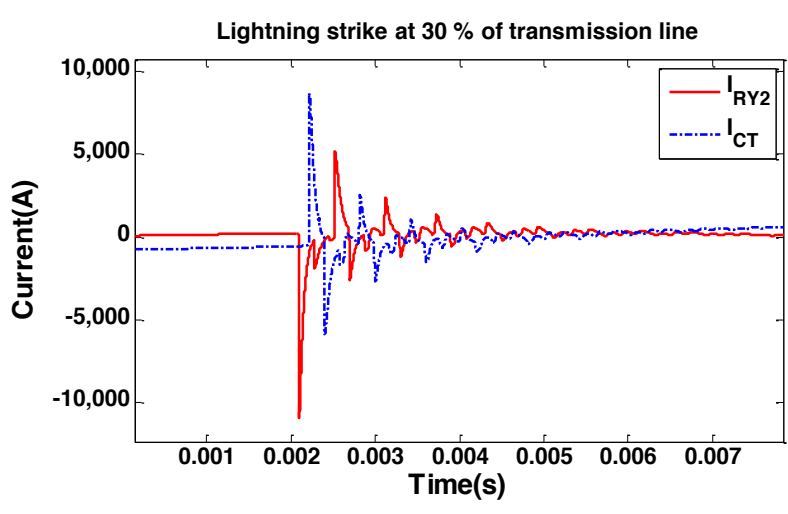

(b) Lightning strike at $30 \%$ of transmission line.

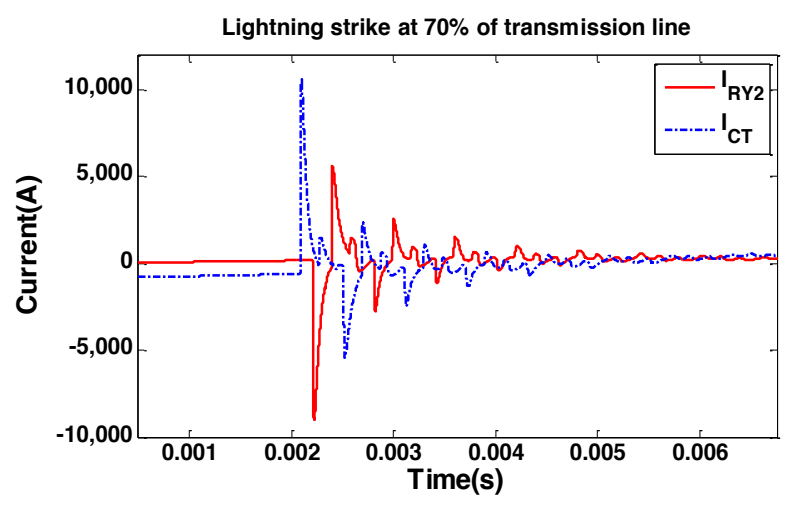

(d) Lightning strike at $70 \%$ of transmission line.

Fig. 2 Positive sequence current waveform for various lengths of the transmission lines.

Table 1. Comparison of variation of peak current and first peak time at various lightning locations of transmission line.

\begin{tabular}{|c|c|c|c|c|}
\hline \multirow{2}{*}{$\begin{array}{c}\text { Location of } \\
\text { lightning }\end{array}$} & \multicolumn{2}{|c|}{ Maximum current (kA) } & \multicolumn{2}{c|}{ First peak time (ms) } \\
\cline { 2 - 5 } & RY2 & CT & RY2 & CT \\
\hline $10 \%$ & -12.708 & 8.014 & 2.033 & 2.280 \\
\hline $30 \%$ & -10.918 & 8.6604 & 2.096 & 2.220 \\
\hline $50 \%$ & -9.8357 & 9.4707 & 2.158 & 2.158 \\
\hline $70 \%$ & -9.0247 & 10.5882 & 2.219 & 2.096 \\
\hline
\end{tabular}

After varying the location of lightning, similarly, the inception angle is varied in order to observe the characteristics of positive sequence current as shown in Fig. 3 and Table 2. By considering the Figure 3, the amplitude of positive sequence current of both substations has a little-impact while the first peak time of positive sequence current of both substations is unchanged as shown in Table 2.

By changing only the amplitude of lightning strikes as shown in Fig. 4 and Table 3, it can be clearly seen that the amplitude of positive sequence current of both substations tends to increase with the increase of amplitude of lightning strikes, but the first peak time of positive sequence current of both substations is also unchanged; this indicates that its change plays an important role for the lightning detection decision algorithm but not for predicting the lightning location.

By changing the voltage level of transmission system as shown in Fig. 5 and Table 4, it can be clearly seen that the amplitude of positive sequence current of both substations tends to decrease with the increase of voltage level of transmission system, but the first peak time of positive sequence current of both substations remains also unchanged; this indicates that the lightning detection decision algorithm obtained is beneficial but not for predicting the lightning location.

By changing the ground resistance of transmission system tower as shown in Fig. 6 and Table 5, the similarity between these waveforms can be clearly seen in terms of the amplitude and the first peak time of positive sequence current for both substations; this indicates that its change has the same behavior as in case of the inception angles. 


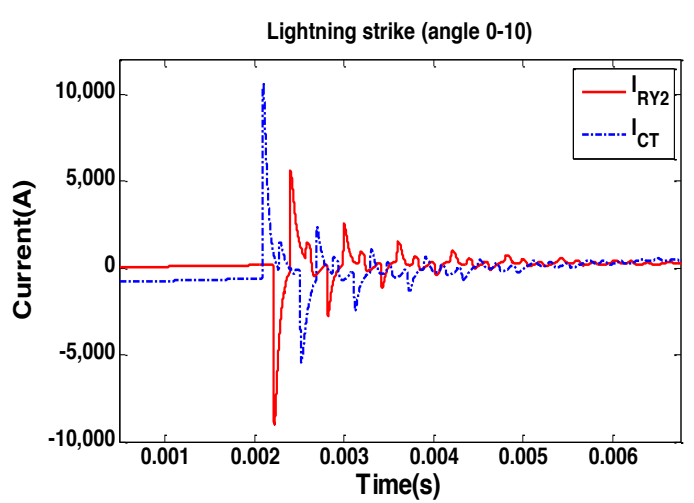

(a) Lightning strike when angle is 0 degree.

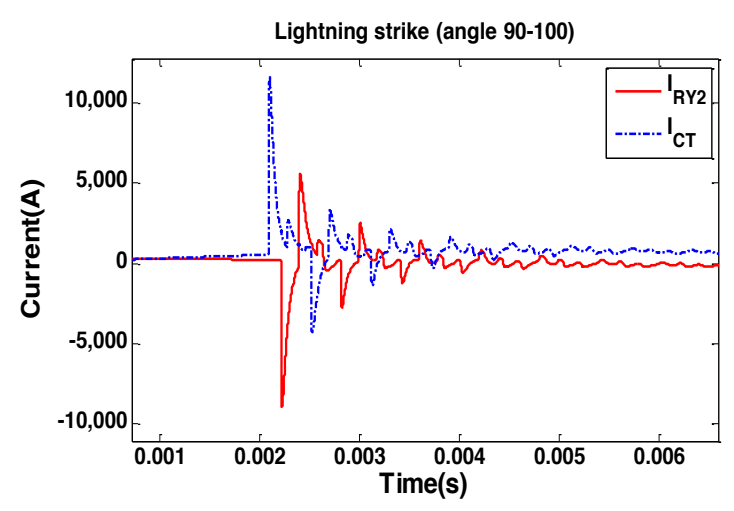

(b) Lightning strike when angle is 90 degree.

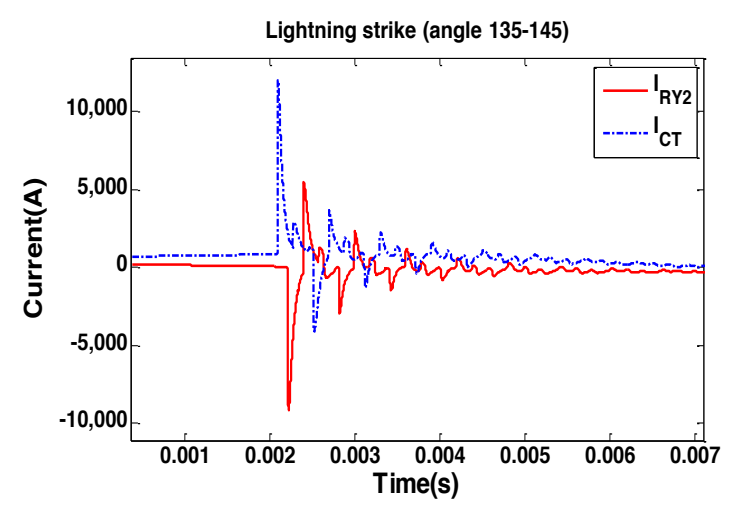

(c) Lightning strike when angle is 135 degree.

Fig. 3 Positive sequence current waveform in case of various inception angles.

Table 2. Comparison of variation of peak current and first peak time at various inception angles.

\begin{tabular}{|c|c|c|c|c|}
\hline \multirow{2}{*}{ nception angle } & \multicolumn{2}{|c|}{ Maximum current (kA) } & \multicolumn{2}{c|}{ First peak time (ms) } \\
\cline { 2 - 5 } & RY2 & CT & RY2 & CT \\
\hline 0 & -9.0247 & 10.5882 & 2.2193 & 2.0960 \\
\hline 90 & -8.9638 & 11.7384 & 2.2193 & 2.0959 \\
\hline 135 & -9.1504 & 12.0033 & 2.2193 & 2.0960 \\
\hline
\end{tabular}

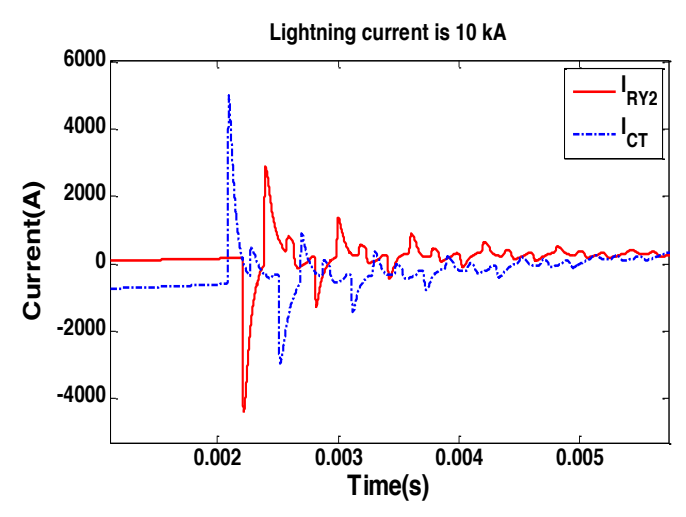

(a) Lightning current of $10 \mathrm{kA}$.

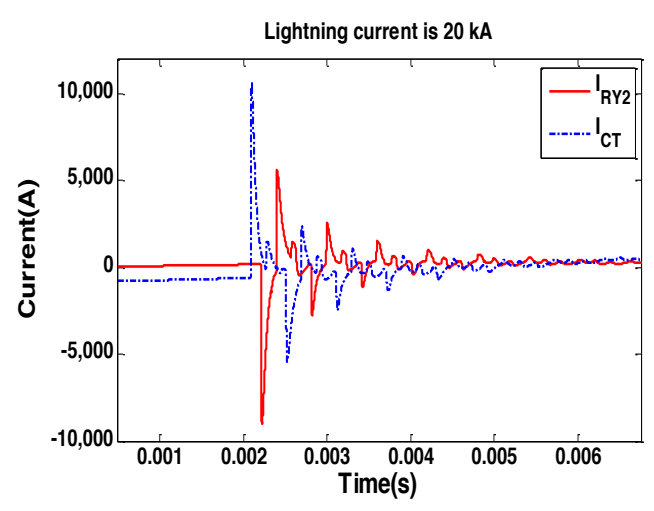

(b) Lightning current of $20 \mathrm{kA}$.

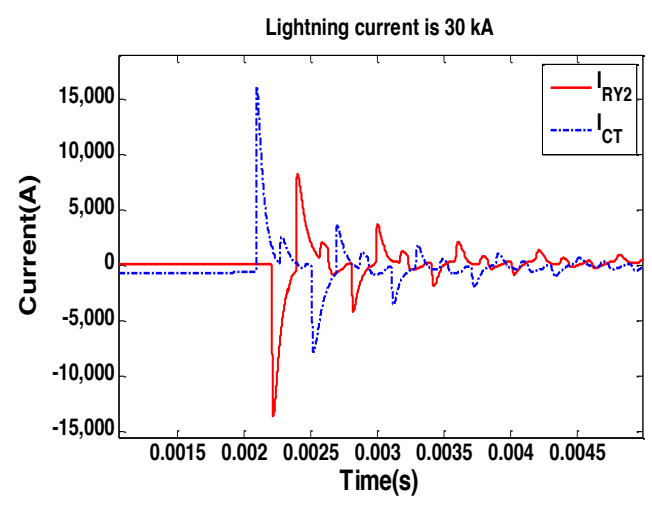

(c) Lightning current of $30 \mathrm{kA}$.

Fig. 4 Positive sequence current waveform in case of various amplitude of lightning strikes.

Table 3. Comparison of variation of peak current and first peak time at various lightning currents.

\begin{tabular}{|c|c|c|c|c|}
\hline \multirow{2}{*}{$\begin{array}{c}\text { Lightning } \\
\text { current }(\mathrm{kA})\end{array}$} & \multicolumn{2}{|c|}{ Maximum current (kA) } & \multicolumn{2}{c|}{ First peak time (ms) } \\
\cline { 2 - 5 } & RY2 & CT & RY2 & CT \\
\hline 10 & -4.4280 & 4.9932 & 2.2193 & 2.0960 \\
\hline 20 & -9.0247 & 10.5882 & 2.2193 & 2.0960 \\
\hline 30 & -13.6210 & 16.1832 & 2.2191 & 2.0960 \\
\hline
\end{tabular}




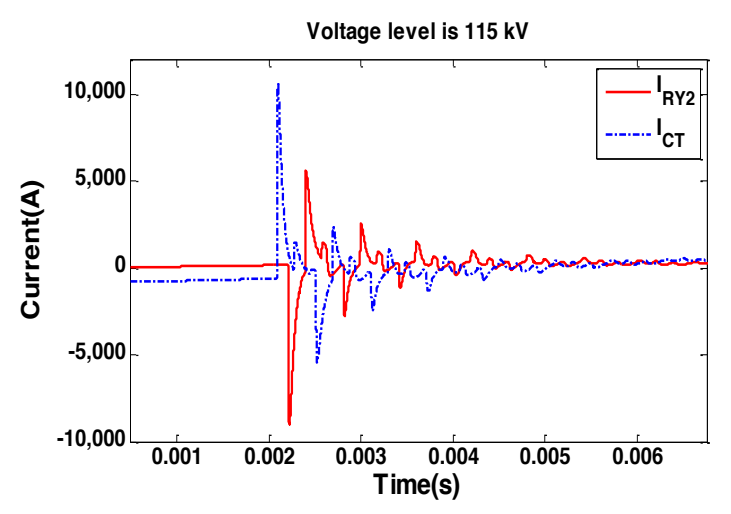

(a) Voltage level of $115 \mathrm{kV}$.

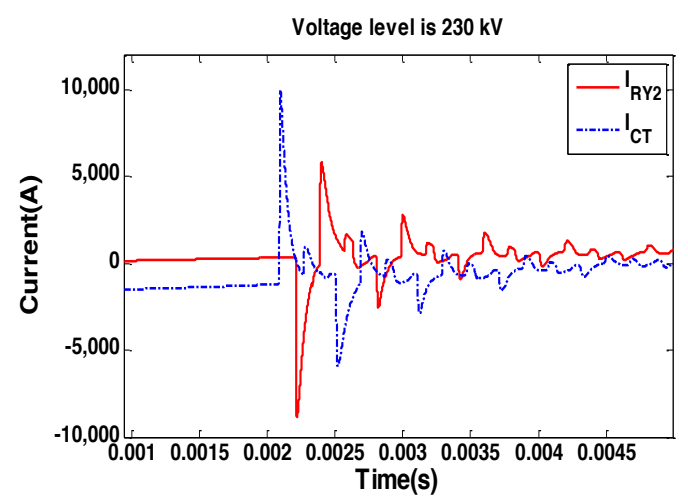

(b) Voltage level of $230 \mathrm{kV}$.

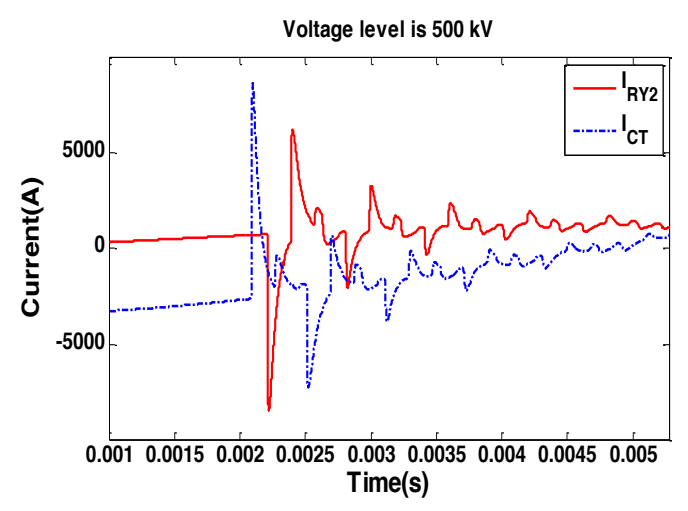

(c) Voltage level of $500 \mathrm{kV}$.

Fig. 5 Positive sequence current waveform in case of various voltage levels of transmission system.

Table 4. Comparison of variation of peak current and first peak time at various voltage levels of transmission systems.

\begin{tabular}{|c|c|c|c|c|}
\hline \multirow{2}{*}{$\begin{array}{c}\text { Voltage level } \\
(\mathrm{kV})\end{array}$} & \multicolumn{2}{|c|}{ Maximum current (kA) } & \multicolumn{2}{c|}{ First peak time (ms) } \\
\cline { 2 - 5 } & $\mathrm{RY} 2$ & $\mathrm{CT}$ & $\mathrm{RY}$ & $\mathrm{CT}$ \\
\hline 115 & -9.0247 & 10.5882 & 2.2193 & 2.0960 \\
\hline 230 & -8.8559 & 9.9865 & 2.2192 & 2.0960 \\
\hline 500 & -8.4597 & 8.5737 & 2.2192 & 2.0960 \\
\hline
\end{tabular}

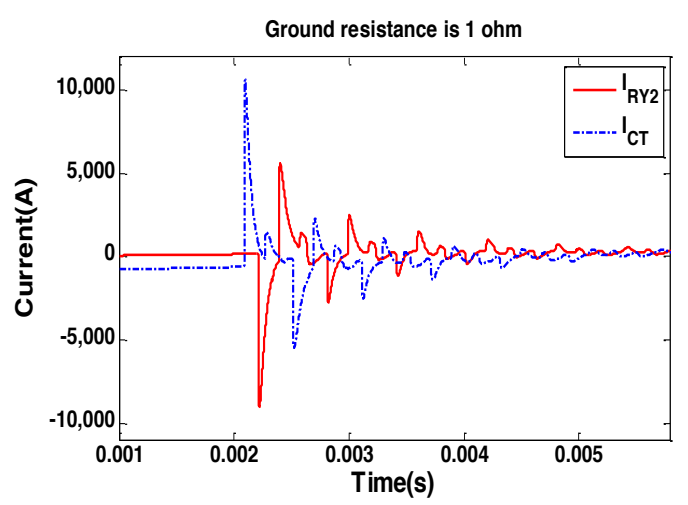

(a) Ground resistance of $10 \mathrm{ohms}$

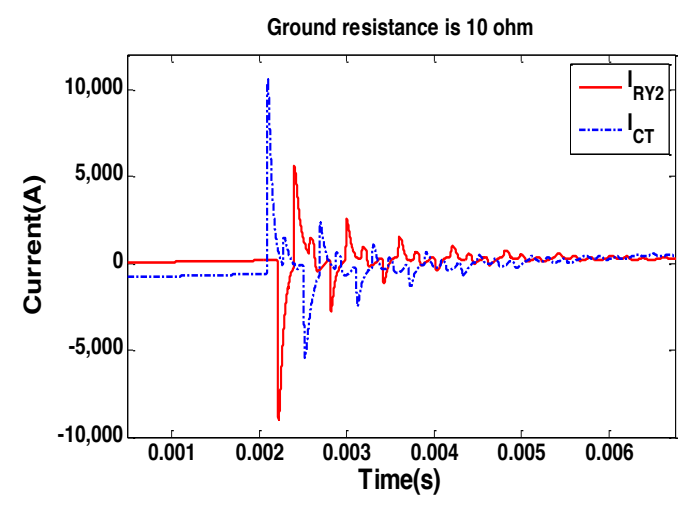

(b) Ground resistance of $10 \mathrm{ohms}$.

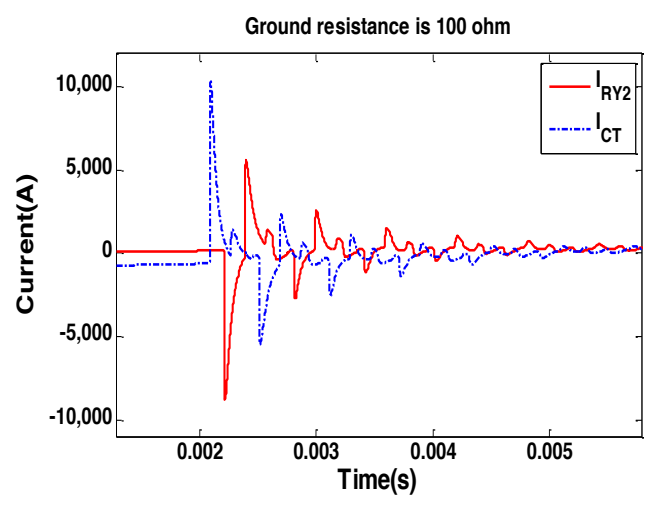

(c) Ground resistance of $100 \mathrm{ohms}$.

Fig. 6 Positive sequence current waveform in case of various ground resistances of transmission system tower.

Table 5. Comparison of variation of peak current and first peak time at various ground resistances of transmission line tower.

\begin{tabular}{|c|c|c|c|c|}
\hline \multirow{2}{*}{$\begin{array}{c}\text { Ground resistance } \\
(\Omega)\end{array}$} & \multicolumn{2}{|c|}{ Maximum current (kA) } & \multicolumn{2}{c|}{ First peak time (ms) } \\
\cline { 2 - 5 } & RY2 & CT & RY2 & CT \\
\hline 1 & -9.0508 & 10.6206 & 2.2193 & 2.0960 \\
\hline 10 & -9.0247 & 10.5882 & 2.2193 & 2.0960 \\
\hline 100 & -8.8303 & 10.3655 & 2.2192 & 2.0960 \\
\hline
\end{tabular}




\section{Identification of lightning location using travelling wave method}

After the characteristics of positive sequence current have been analysed with various case studies, the characteristics of positive sequence current are necessary to understand variation of first peak time of positive sequence current before calculating the lightning location. The location of lightning can be calculated by using the equation 1 .

$$
X=\frac{L+v\left(T_{1 R Y 2}-T_{1 C T}\right)}{2}
$$

Where:

$\mathrm{X}$ is the location of lightning, measured from the sending end substation (RY2) or lightning location (km)

$\mathrm{L}$ is the length of total line of transmission line on which the fault is detected $(\mathrm{km})$

$v$ is the velocity of the travelling wave $(\mathrm{m} / \mu s)$

(In this paper, the travelling wave speed is $298.85 \mathrm{~m} / \mu \mathrm{s}$ )

$T_{1 R Y 2}$ is the time of first peak time, arriving at sending end substation (ms)

$T_{1 C T}$ is the time of first peak time, arriving at receiving end substation (ms)

After calculating the travelling wave equation with the various case studies, the obtained results were presented in Tables 6-8. By considering data in Table 6, case studies were performed with various inception angles, the amplitude of lightning current, and the ground resistance of transmission tower; it can be seen that the obtained results is satisfactory with a mean error of less than $1 \mathrm{~km}$.
Similarly, case studies were performed with various voltage levels of transmission system including the variation of inception angle, lightning current, and ground resistance as shown in Table 7; it can be seen that the accuracy of lightning location from the predication of the proposed technique was also satisfactory. However, when the location of lightning was varied as shown in Table 8 , it can be seen that the error of lightning location from the proposed technique tends to decrease with increasing the distance between lightning point and sending end substation and tends to increase with decreasing the distance between lightning point and receiving end substation. In order to overcome this problem, a new technique should be developed in order to able to predict the lightning location more precisely.

\section{Conclusion}

In this paper, the travelling wave technique was employed in order to predict the location of lightning along the transmission line. Time of first wave arrival at both ends of line, detected by current transformer (CT) at both sides, are investigated as input data for travelling wave equation. The case studies were performed with various parameters such as inception angle, location of lightning, ground resistance of tower, amplitude of lightning strikes, and voltage level of transmission line, in order to evaluate the accuracy of the proposed technique. By considering the overall results, it can be seen that the average error of proposed technique is less than $1 \mathrm{~km}$. The further work will be the improvement of the new technique to be able to predict the lightning location more precisely.

Table 6. Results of lightning location for various case studies (Lightning at $61.95 \mathrm{~km}$ ).

\begin{tabular}{|c|c|c|c|c|c|c|c|}
\hline \multirow{2}{*}{$\begin{array}{l}\text { Real location of } \\
\text { lightning }(\mathrm{km})\end{array}$} & \multirow{2}{*}{$\begin{array}{c}\text { Inception } \\
\text { angle }\end{array}$} & \multirow{2}{*}{$\begin{array}{l}\text { Lightning } \\
\text { current (kA) }\end{array}$} & \multirow{2}{*}{$\begin{array}{c}\text { Ground } \\
\text { resistance }(\Omega)\end{array}$} & \multicolumn{2}{|c|}{ First peak time (ms) } & \multicolumn{2}{|c|}{ Lightning location $(\mathrm{km})$} \\
\hline & & & & RY2 & $\mathrm{CT}$ & Calculation & Error \\
\hline \multirow{3}{*}{61.95} & 0 & 20 & 10 & 2.219 & 2.096 & 62.629275 & -0.679275 \\
\hline & 90 & 20 & 10 & 2.219 & 2.096 & 62.629275 & -0.679275 \\
\hline & 135 & 20 & 10 & 2.219 & 2.096 & 62.629275 & -0.679275 \\
\hline \multirow{3}{*}{61.95} & 0 & 10 & 10 & 2.219 & 2.096 & 62.629275 & -0.679275 \\
\hline & 0 & 20 & 10 & 2.219 & 2.096 & 62.629275 & -0.679275 \\
\hline & 0 & 30 & 10 & 2.219 & 2.096 & 62.629275 & -0.679275 \\
\hline \multirow{3}{*}{61.95} & 0 & 20 & 1 & 2.219 & 2.096 & 62.629275 & -0.679275 \\
\hline & 0 & 20 & 10 & 2.219 & 2.096 & 62.629275 & -0.679275 \\
\hline & 0 & 20 & 100 & 2.219 & 2.096 & 62.629275 & -0.679275 \\
\hline
\end{tabular}


Table 7. The results from travelling wave method for lightning location in case of various voltages level of transmission system.

\begin{tabular}{|c|c|c|c|c|c|c|c|}
\hline \multirow{3}{*}{ Voltage Level $(\mathrm{kV})$} & \multirow{2}{*}{$\begin{array}{c}\text { Inception } \\
\text { angle }\end{array}$} & \multirow{2}{*}{$\begin{array}{c}\text { Lightning } \\
\text { current }(\mathrm{kA})\end{array}$} & \multirow{2}{*}{$\begin{array}{c}\text { Ground } \\
\text { resistance }(\Omega)\end{array}$} & \multicolumn{2}{|c|}{ First peak time $(\mathrm{ms})$} & \multicolumn{2}{|c|}{ Lightning location $(\mathrm{km})$} \\
\cline { 5 - 8 } & 0 & 20 & 10 & 2.219 & 2.096 & 62.629275 & -0.679275 \\
\hline \multirow{3}{*}{115} & 90 & 20 & 10 & 2.219 & 2.096 & 62.629275 & -0.679275 \\
\cline { 2 - 8 } & 135 & 20 & 10 & 2.219 & 2.096 & 62.629275 & -0.679275 \\
\hline \multirow{3}{*}{230} & 0 & 10 & 10 & 2.219 & 2.096 & 62.629275 & -0.679275 \\
\cline { 2 - 8 } & 0 & 20 & 10 & 2.219 & 2.096 & 62.629275 & -0.679275 \\
\cline { 2 - 8 } & 0 & 30 & 10 & 2.219 & 2.096 & 62.629275 & -0.679275 \\
\hline \multirow{3}{*}{500} & 0 & 20 & 1 & 2.219 & 2.096 & 62.629275 & -0.679275 \\
\cline { 2 - 8 } & 0 & 20 & 10 & 2.219 & 2.096 & 62.629275 & -0.679275 \\
\cline { 2 - 8 } & 0 & 20 & 100 & 2.219 & 2.096 & 62.629275 & -0.679275 \\
\hline
\end{tabular}

Table 8. The results from travelling wave method at different locations of lightning along the transmission line.

\begin{tabular}{|c|c|c|c|c|c|c|c|}
\hline Real location of & \multirow{2}{*}{$\begin{array}{c}\text { Inception } \\
\text { lightning }(\mathrm{km})\end{array}$} & \multirow{2}{*}{$\begin{array}{c}\text { Lightning } \\
\text { angle }\end{array}$} & \multirow{2}{*}{$\begin{array}{c}\text { Ground } \\
\text { current }(\mathrm{kA})\end{array}$} & resistance $(\Omega)$ & First peak time $(\mathrm{ms})$ & \multicolumn{2}{|c|}{ Lightning location $(\mathrm{km})$} \\
\cline { 5 - 8 } & 0 & 20 & 10 & 2.033 & 2.280 & 7.282255 & 1.567745 \\
\hline 8.85 & 0 & 20 & 10 & 2.065 & 2.250 & 16.576490 & 1.12351 \\
\hline 17.70 & 0 & 20 & 10 & 2.096 & 2.220 & 25.825897 & 0.724103 \\
\hline 26.55 & 0 & 20 & 10 & 2.127 & 2.189 & 35.075305 & 0.324695 \\
\hline 35.40 & 0 & 20 & 10 & 2.158 & 2.158 & 44.250 & 0 \\
\hline 44.25 & 0 & 20 & 10 & 2.189 & 2.127 & 53.439637 & -0.339637 \\
\hline 53.10 & 0 & 20 & 10 & 2.219 & 2.096 & 62.629275 & -0.679275 \\
\hline 61.95 & 0 & 20 & 10 & 2.250 & 2.065 & 71.893625 & -1.093625 \\
\hline 70.80 & 0 & 20 & 10 & 2.280 & 2.033 & 81.068320 & -1.41832 \\
\hline 79.65 & & & & & & & \\
\hline
\end{tabular}

\section{Acknowledgment}

The authors wish to gratefully acknowledge financial support for this research from the King Mongkut's Institute of Technology Ladkrabang Research fund, Thailand. The authors would like also to thank for partially supported by the Faculty of Engineering, Rajamangala University of Technology Rattanakosin Research fund.

\section{References}

(1) He Jinliang, Tu Youping, Zeng Rong, J.B. Lee, S.H. Chang and Guan Zhicheng : "Numeral analysis model for shielding failure of transmission line under lightning stroke", IEEE Transactions on Power Delivery, Vol. 20, No. 2, pp. 815-822, April 2005.
(2) B. Vahidi, M. Yahyaabadi, M.R.B. Tavakoli and S.M. Ahadi : "Leader Progression Analysis Model for Shielding Failure Computation by Using the Charge Simulation Method", IEEE Transactions on Power Delivery, Vol. 23, No. 4, pp. 2201-2206, Oct. 2008.

(3) Wei Bengang, Fu Zhengcai and Yuan Haiyan : "Analysis of Lightning Shielding Failure for 500-kV Overhead Transmission Lines Based on an Improved Leader Progression Model", IEEE Transactions on Power Delivery, Vol. 24, No. 3, pp. 1433-1440, July 2009.

(4) M.R.B. Tavakoli and B. Vahidi : "Transmission-Lines Shielding Failure-Rate Calculation by Means of 3-D Leader Progression Models", IEEE Transactions on Power Delivery, Vol. 26, No. 2, pp. 507-516, April 2011.

(5) P.N. Mikropoulos and T.E. Tsovilis : "Estimation of the shielding performance of overhead transmission lines: the effects of lightning 
attachment model and lightning crest current distribution", IEEE Transactions on Dielectrics and Electrical Insulation, Vol. 19, No. 6, pp. 2155-2164, December 2012.

(6) A. Borghetti, C.A. Nucci, and M. Paolone : "Estimation of the statistical distributions of lightning current parameters at ground level from the data recorded by instrumented towers", IEEE Transactions on Power Delivery, Vol. 19, No. 3, pp. 1400-1409, July 2004.

(7) Jun Takami : "Observational Results of Lightning Current on Transmission Towers," IEEE Transactions on Power Delivery, Vol. 22, No. 1, pp. 547-556, Jan. 2007.

(8) A. Ametani, N. Nagaoka, T. Funabashi, and N. Inoue : "Tower Structure Effect on a Back-Flashover Phase", Proceedings of International Conference on Power Systems Transients (IPST'05), Paper No. IPST05 - 190, Montreal, Canada, 19-23 June 2005.

(9) Han Yongxia, Tang Li, Li Licheng, He Qiuping, Hao Yanpeng and Yao Senjing : "Influence of Lightning Flashover Criterion on the Calculated Lightning withstand Level of $\pm 800 \mathrm{kV}$ UHVDC Transmission Lines at High Altitude”, IEEE Transactions on Dielectrics and Electrical Insulation, Vol. 22, No. 1, pp. 185-191, February 2015.

(10) K. Fekete1, S. Nikolovski, G. Knezević, M. Stojkov and Z. Kovač : "Simulation of Lightning Transients on $110 \mathrm{kV}$ overhead-cable transmission line using ATP-EMTP," $15^{\text {th }}$ IEEE Mediterranean Electrotechnical Conference (MELECON2010), pp. 856-861, April 2010.

(11) Sima Wenxia, Lan Xing, Yang Qing and Tao Yuan : "Statistical analysis on measured lightning overvoltage surges in a $110 \mathrm{kV}$ air-insulated substation”, IET Science, Measurement \& Technology, Vol. 9, No. 1, pp. 28-36, January 2015.

(12) Jun Takami, Toshihiro Tsuboi, Keisuke Yamamoto and Shigemitsu Okabe : "FDTD Simulation Considering an AC Operating Voltage for Air-insulation Substation in Terms of Lightning Protective Level", IEEE Transactions on Dielectrics and Electrical Insulation, Vol. 22, No. 2, pp. 806-814, April 2015.

(13) Felix Goll and Rolf Witzmann : "Lightning Protection of 500-kV DC Gas-Insulated Lines (GIL) With Integrated Surge Arresters", IEEE Transactions on Power Delivery, Vol. 30, No. 3, pp. 1602-1610, June 2015.

(14) Xue Simin, Yuan Ping, Cen Jianyong, Liu Jianguo, and Li Yajun : "Study on Physical Characteristics of a Bipolar Cloud-to-Ground Lightning Discharge Plasma”, IEEE Transactions on Plasma Science, Vol. 43, No. 3, pp. 851-856, March 2015.
(15) Anna Candela Garolera, Kenneth L. Cummins, Soren Find Madsen, Joachim Holboell, and Jackson D. Myers : "Multiple Lightning Discharges in Wind Turbines Associated With Nearby Cloud-to-Ground Lightning", IEEE Transactions on Sustainable Energy, Vol. 6, No. 2, pp. 526-533, April 2015.

(16) N.N.C. Corona, F. Trillaud, and F.R.P. Segura : "Direct Current Lightning Tests on Optical Ground Wires", IEEE Latin America Transactions, Vol. 13, No. 3, pp. 640-644, March 2015.

(17) Wang Jufeng, Liu Jinlian, Wu Guoqiang, Liu Qiliang, and Guo Wei : "Research and Application of Jet Stream Arc-quenching Lightning Protection Gap (JSALPG) for Transmission Lines", IEEE Transactions on Dielectrics and Electrical Insulation, Vol. 22, No. 2, pp. 782-788, April 2015.

(18) Toshihiro Tsuboi, Jun Takami, Shigemitsu Okabe, Takayuki Kido, and Toshihiro Maekawa : "Energy Absorption Capacity of a $500 \mathrm{kV}$ Surge Arrester for Direct and Multiple Lightning Strokes", IEEE Transactions on Dielectrics and Electrical Insulation, Vol. 22, No. 2, pp. 916-924, April 2015.

(19) Huangfu Youpeng, Wang Shuhong, Wang Guolin, Xu Weijie, and Zhang Haijun : "Modeling and Insulation Performance Analysis of Composite Transmission Line Tower Under Lightning Overvoltage", IEEE Transactions on Magnetics, Vol. 51, No. 3, pp. 1-4, March 2015.

(20) Sisira James, Nihal Kularatna, Alistair Steyn-Ross, Rainer Kunnemeyer : "Estimation of transient surge energy transferred with associated time delays for individual components of surge protector circuits", IET Power Electronics, Vol. 8, No. 5, pp. 685-692, May 2015.

(21) Shigemitsu Okabe, Toshihiro Tsuboi, and Genyo Ueta : "Uncertainty in K-factor Measurement for Lightning Impulse Voltage Test”, IEEE Transactions on Dielectrics and Electrical Insulation, Vol. 22, No. 1, pp. 266-277, February 2015.

(22) Carlos R. Hall Barbosa, Jari Hallstrom, Marcio Thelio Fernandes da Silva, Luiz Carlos Azevedo, and Lucas Castro Faria : "Tail-Chopped Lightning Impulses Time Parameters Estimated According to Standard IEC 60060-1:2010”, IEEE Transactions on Instrumentation and Measurement, Vol. 64, No. 6, pp. 1369-1372, June 2015.

(23) P. Lertwanitrot, P. Kettranan, P. Itthisathienkul and A. Ngaopitakkul : "Characteristics and Behaviour of Transient Current during Lightning Strikes on Transmission Tower", Proceedings of the International MultiConference of Engineers and Computer Scientists, Vol. II, pp. 708-7131, March 2015. 